\title{
Saturnino de Brito \\ e o traçado sanitário \\ da cidade de \\ Santa Maria/RS
}

\author{
Dirceu Piccinato Junior*
}

Resumo o objetivo do presente artigo é discutir sobre o traçado sanitário de Santa Maria, cidade do estado do Rio Grande do Sul, sob a perspectiva da forma urbana sanitarista articulada pelo engenheiro sanitarista Saturnino de Brito em 1918. O processo de urbanização que aconteceu a partir das primeiras décadas do século XX foi determinante para o crescimento das cidades brasileiras em condições socioambientais inadequadas. Com os avanços da microbiologia, surge a figura de um profissional que tinha domínio para atuar frente a essa realidade: o engenheiro sanitarista. A compreensão do urbanismo sanitarista de Brito tinha como desígnio dois temas: os problemas de salubridade na transformação dos espaços urbanos e a construção das cidades.

Palavras-chave: traçado sanitário, forma urbana, Santa Maria/RS.

\section{Saturnino de Brito y el proyecto sanita- rio de la ciudad de Santa Maria/RS}

\begin{abstract}
Resumen El propósito de este artículo es discutir el diseño sanitario de Santa María, una ciudad en el estado de Rio Grande do Sul, desde la perspectiva de la forma sanitaria urbana articulada por el ingeniero sanitario Saturnino de Brito en 1918. El proceso de urbanización que tuvo lugar desde el Las primeras décadas del siglo XX fueron decisivas para el crecimiento de las ciudades brasileñas en condiciones socioambientales inadecuadas. Con los avances en microbiología, aparece la figura de un profesional que tenía el dominio para actuar frente a esta realidad: el ingeniero sanitario. La comprensión del urbanismo sanitario de Brito tenía dos temas en mente: los problemas de salud en la transformación de espacios urbanos y la construcción de ciudades.
\end{abstract}

Palabras clave: diseño sanitario, forma urbana, Santa María/ RS.

\section{Saturnino de Brito and Sanitary Layout of the city of Santa Maria/RS}

\begin{abstract}
The purpose of this article is to discuss the sanitary layout of Santa Maria, a city in the state of Rio Grande do Sul, from the perspective of the urban sanitary form articulated by sanitary engineer Saturnino de Brito in 1918. The urbanization process that took place from the first decades of the 20th century was decisive for the growth of Brazilian cities in inadequate socio-environmental conditions. With the advances in microbiology, there appears the figure of a professional who had the domain to act in the face of this reality: the sanitary engineer. Brito's understanding of sanitary urbanism had two themes in mind: health problems in the transformation of urban spaces and the construction of cities.
\end{abstract}

Keywords: sanitary layout, urban form, Santa Maria/RS. 
O

termo cidade, no decorrer dos tempos, caracterizou-se por diferentes abordagens, pois ela é um fenômeno em constante transformação. Todavia, não há a intenção de se estabelecer uma etimologia da palavra, mas brevemente compreender sua dimensão frente à estruturação sanitária das cidades durante a primeira metade do século XX no Brasil. Pode-se conceituar cidade como forma de assentamento humano com predominância de concentração e densidade elevada de pessoas, de bens, de infraestrutura, de objetos, entre outros elementos, e que envolve um saber, um conhecimento. A cidade se constitui historicamente numa forma do ambiente construído.

A palavra cidade está em questão. De um lado, como fonte de esperanças e de utopias, a cidade tem sido, por excelência, o lugar dos desejos e das angústias modernas; de outro, atualmente, nela prevalecem a violência e os medos sociais. Esses dois lados apontam para a importância de reconstruir os meios de falar e pensar a cidade. Dentro de uma dimensão histórica do início do século XX, cidade pode ser definida por seu aparelhamento diferenciado e privilegiado de sediar a autoridade. Não se define necessariamente pelo tamanho, mas sobretudo pelo contraste entre grupos sociais (PEREIRA, 2001).

Se é a cidade um conjunto e reflexo de objetos e conhecimentos construído num tempo e num espaço, consequentemente, ela ganhou forma. Assim, a dimensão física da cidade, isto é, sua forma, seu traçado, é o que nos permitirá compreender a realidade do ambiente construído, já que ele traz consigo informações sobre ideologias, práticas urbanas, condições econômicas e culturais, posicionamento político e, especialmente, relações sociais. Segundo Philippe Panerai, Jean Castex e Jean-Charles Depaule (2013) a realidade do ambiente construído também permite analisar a mudança entre discurso e prática.

A estruturação sanitária das cidades aliou, em sua implementação, discurso e prática. O engenheiro sanitarista Saturnino de Brito foi quem melhor expressou esse contexto no Brasil. De formação francesa, desenvolveu planos de saneamento e melhoramentos urbanos para muitas cidades brasileiras, num período em que a ameaça de epidemias exigia intervenções sanitárias urgentes.

A atuação profissional do referido engenheiro percorreu um total de 53 cidades brasileiras; destas, 13 são localizadas no Rio Grande do Sul. A primeira cidade gaúcha a receber intervenções de Saturnino de Brito foi a cidade do Rio Grande, em 1909 e, depois, em 1921. Entre os anos de 1918 e 1919, cinco cidades gaúchas recorreram aos

* Dirceu Piccinato Junior é Arquiteto e Urbanista, Professor da Faculdade de Arquitetura e Urbanismo da Faculdade Meridional. ORCID <http://orcid.org/00000001-5153-0931>. serviços do engenheiro sanitarista para a elaboração de seus planos de saneamento e de ampliação de suas redes de água e esgoto: Santa Maria, Cachoeira, Cruz Alta, Passo Fundo e Rosário. No ano de 1920, foi a cidade de Santana do Livramento que requisitou o trabalho do engenheiro para realizar o seu saneamento. No ano de 1922, Saturnino de Brito atuou no saneamento e projeto de expansão urbana da cidade 
de São Leopoldo. Entre 1923 e 1924, Uruguaiana, Iraí e São Gabriel solicitaram ao engenheiro que elaborasse obras para o seu saneamento urbano. Em 1927, Saturnino de Brito elaborou planos de saneamento e de expansão da rede de água e esgoto para as cidades de Alegretes e Pelotas (LOPES, 2013).

Nesse momento, primeira metade do século $X X$, de maneira geral, devido às suas condições urbanas, as cidades solicitavam a presença de eruditos no campo urbano para atender à demanda de problemas que se apresentavam. As cidades eram consideradas insalubres, com sujeira pelas vias, ruas esburacadas e alagadiças em dias chuvosos. As doenças geradas pela falta de higiene e saneamento causaram a morte de muitos cidadãos. O esgoto in natura circulava pelos logradouros juntamente com o cidadão. O mau cheiro acompanhava o passante. A água para consumo ficava distante das moradias. A iluminação à noite era precária ou ausente em muitas realidades. $\mathrm{O}$ traçado urbano desenvolvido na maioria das cidades dificultava a vida de seus moradores. Foi em meio a essa realidade que o engenheiro sanitarista Saturnino de Brito atuou com seus planos de melhoramentos.

Frente a esse contexto, o objetivo deste trabalho é analisar e caracterizar a estruturação sanitária de uma cidade, ou seja, estabelecer uma compreensão a partir dos preceitos teóricos e da prática sanitários empregados por Saturnino de Brito na cidade de Santa Maria/RS. Esse movimento para entender as cidades e atuar sobre elas frente às dificuldades que emergiam permitiram que Brito desenvolvesse, se não um método, uma prática que definiu diretamente uma forma urbana. É dentro dessa dimensão que o debate se torna pertinente. Estudos sobre o ideário e prática desse engenheiro sanitarista contribuem para se estabelecer uma melhor compreensão do corpus urbanismo no Brasil, particularmente quando as análises são de uma cidade de pequeno porte do interior do país, à época.

Na primeira parte (introdução) são apresentadas, em síntese, as questões conceituais que permeiam o texto, bem como a perspectiva de forma e cidade. Na parte seguinte, pretende-se expor os conceitos, aspectos, características e exemplos que denotam a ideia de forma urbana a partir do traçado sanitário das cidades. Para Maria Lucia Caira Gitahy (2005), tal processo significou que construir infraestrutura moderna, requalificando as relações espaciais urbanas, não foi apenas uma tarefa de construção física, mas também de instituições sociais voltadas para a busca intelectual e para a redefinição das relações sociais. Na terceira parte deste texto, destaca-se o estudo acerca do traçado sanitário de Santa Maria/RS. O plano de melhoramentos urbanos elaborado por Saturnino de Brito foi o primeiro "projecto" urbano para a cidade, o que configurou um referencial para planos futuros, além de, e particularmente, espacializar um discurso e uma prática. Por fim, na última parte (considerações finais), pondera-se a representatividade do traçado sanitário como fonte de estudo e compreensão da forma urbana de muitas cidades atualmente.

\section{Saturnino de Brito e discurso sanitarista sobre as cidades}

Saturnino de Brito ingressou na Escola Politécnica do Rio de Janeiro no ano de 1881 e formou-se em engenharia civil em 1886. De 1887 a 1892, exerceu seu primeiro emprego como engenheiro civil na estrada de Ferro Leopoldina. Em 1893, interrompeu sua carreira, por um ano, para servir a causa do governo nacional como voluntário. No 
ano de 1894, restabeleceu sua vida profissional como engenheiro da Carta Cadastral do Rio de Janeiro e, no ano seguinte, fez o levantamento das plantas e a organização dos projetos de saneamento da cidade de Vitória, estado do Espírito Santo. Em 1896, trabalhou como engenheiro da Comissão de Saneamento do Estado de São Paulo. A partir de 1898, passou a realizar inúmeros trabalhos para as mais diferentes cidades do Brasil. Sua atuação profissional percorreu inúmeras cidades brasileiras, onde pôde expor suas ideias e aplicá-las particularmente na área de saneamento e embelezamento das cidades (LEME (coord.), 1999).

Os planos de melhoramentos urbanos, contemplando o saneamento, a circulação e o embelezamento eram planos urbanísticos relacionados ao campo da engenharia sanitária. A palavra urbanismo não havia sido difundida ainda, mas logo viria substituir o termo melhoramentos. Maria Stella Bresciani (2001) revela que a longa permanência da palavra melhoramentos para designar os mais diferentes benefícios feitos na cidade apresenta, na verdade, outras possibilidades de compreensão. Para a pesquisadora, essa palavra caracteriza-se pela crise provocada pela relação entre o aumento da população, de suas atividades, em particular a comercial, e portanto, da circulação de veículos, e a expansão natural da cidade, corrigindo-a de modo a assegurar o seu desenvolvimento em condições adequadas.

Nessa relação entre espaço construído e espaço a ser construído (expansão da cidade), os melhoramentos dão prioridade aos fluxos, conferindo menor importância ao espaço construído, que deve respeitar os dispositivos técnicos da boa circulação e dos fluxos de ar e sol. Melhorar é mover obstáculos e assegurar vários fluxos em movimento, mas com arte. A palavra melhoramentos recobre um campo de atuação no qual as noções sanitárias, já incorporadas ao vocabulário técnico da engenharia, se expressam na forma de equilíbrio volumétrico numa projeção ordenada da cidade (BRESCIANI, 2001).

1 Victor da Silva Freire nasceu em Lisboa, de pais brasileiros. Formou-se em engenharia civil pela Escola Politécnica de Lisboa (1885 - 1888) e completou sua formação acadêmica na École National des Ponts et Chaussés de Paris (1889 - 1891). Quando chegou ao Brasil, em 1895, foi trabalhar na Superintendência de Obras Públicas, em São Paulo. As trajetórias de Victor da Silva Freire e de Saturnino de Brito se cruzam em São Paulo, quando trabalharam na referida Superintendência, no serviço de abastecimento de água e esgoto. A carreira profissional de Saturnino de Brito se orientou na expertise para municípios em vários estados brasileiros, enquanto Silva Freire passou a integrar definitivamente os serviços da Prefeitura de São Paulo, mantendo uma relação ambígua com o setor privado, particularmente com a Companhia City of São Paulo Improvements (BERTONI, 2015a).
Ao analisar as ideias de Victor da Silva Freire ${ }^{1}$ a partir do termo melhoramentos, ou o que significa esse termo para sua obra, Bresciani (2001) argumenta que os melhoramentos urbanos deveriam respeitar o traçado original da cidade, respeitando, todavia, a simetria do tempo, a simetria artística, do equilíbrio de massas, das proporções, a ordenação artística, em nítido contraste com a simetria seca, em torno de um ponto, de uma linha.

Segundo José Geraldo Simões Junior (2013) a influência de modelos e práticas urbanísticas advindas do cenário internacional estava fortemente marcada pelo poder exercido pela cultura francesa sobre nossas elites e governantes, particularmente pelo ideário de República e suas diferentes conotações simbólicas e positivistas. A referência urbanística era o plano que o prefeito Haussmann tinha executado para a cidade de Paris na década de 1850, reconfigurando a malha urbana e viária medieval da área central, rasgando largas avenidas e implantando sistemas modernos de infraestrutura, espaços públicos, áreas verdes, edifícios públicos, além de uma padronização estética para as novas construções.

Quanto ao aspecto sanitário, as novas orientações da medicina e da saúde pública a partir de Pasteur contribuíram para o enfrentamento de problemas de saúde do indivíduo e da cidade. No campo da engenharia, a contribuição aconteceria por meio de planos integrados de saneamento envolvendo drenagem, canalização de cursos 
d'água, tratamento de esgotos e abastecimento de água potável. O maior expoente brasileiro foi Francisco Saturnino Rodrigues de Brito (SIMÕES JUNIOR, 2013).

Para Bertoni (2015a), o trabalho de Camillo Site foi particularmente útil para Saturnino de Brito. As ferramentas de análise desenvolvidas por Sitte na sua obra "Construção das Cidades segundo seus Princípios Artísticos" foram apropriadas por Saturnino para apoiar a demonstração de uma colaboração importante entre técnicos e urbanistas. 0 estabelecimento de um plano geral era essencial para nortear o crescimento ordenado das cidades, isto é, o primeiro elemento a se considerar era a definição das redes técnicas, que deveriam tirar proveito de encostas naturais para reduzir os custos de implementação, ou seja, a definição de uma topografia sanitária. Bertoni acrescenta ainda que Saturnino demonstrava profunda sensibilidade e experiência quando discutia a questão das linhas reta e curva das ruas, lembrando que os efeitos pitorescos não poderiam ser considerados em detrimento da eficácia sanitária.

Dentro da obra de Camillo Sitte observa-se que o sentimento artístico estava presente na formação ao acaso das cidades antigas, contudo, não se apresentava mais na formação da cidade moderna. Dessa forma, para Brito, segundo os estudos de Daniel Tochetto de Oliveira (2013), deixar a construção da cidade ao acaso provocaria a desordem, sem planos e sem normas, cada um poderia construir de maneira diferente de seu vizinho e conforme lhe aprouvesse. Tanto Sitte como Brito possuíam preocupações em comum, como a construção desordenada da cidade pela falta de regras. Mas Sitte estava mais preocupado com o que se aprenderia com o passado, enquanto Brito, embora considerasse o passado também importante, defendeu a necessidade de estabelecer princípios reguladores para o crescimento, preocupando-se com o futuro. Desse modo, Sitte se preocupou com a preservação da cidade; já Saturnino de Brito se preocupou, especialmente, em planejá-la, pensar o seu futuro, embora não desconsiderasse a importância de preservá-la.

Ao analisar a obra de Saturnino de Brito, o livro Notes sur le tracé sanitaire des villes (Notas sobre o traçado sanitário das cidades), escrito em francês, Angelo Bertoni (2015a) esclarece que a compreensão do urbanismo sanitário de Brito tinha como desígnio dois temas: um dizia respeito aos problemas de salubridade na transformação dos espaços urbanos e na construção das cidades; o outro, às competências profissionais e ao diálogo entre as ciências. A abordagem defendida por Saturnino de Brito está fundamentada na engenharia sanitária, sua ciência de referência, mas ele amplia o ideário para além do saneamento urbano ao projetar intervenções em áreas urbanas existentes e a criar.

Outra conjuntura a ser ressaltada, não só no pensamento de Saturnino de Brito, é que a preocupação com a salubridade acabou por induzir a introdução de novos espaços arborizados e livres na configuração física das cidades, considerados de suma importância para a saúde da população. No sentido de associar materialmente essa preocupação, acabaram emergindo diferentes programas de conservação dos parques existentes e obras de reforma viária das áreas centrais, que imprimiram novos cenários, novos usos e novas sociabilidades no espaço intraurbano das cidades (DANTAS, 2003).

De modo geral, Saturnino de Brito procurou intervir o mínimo possível no traçado existente das cidades em que atuou. Suas intervenções, resumidamente, pautavam-se 
na abertura de vielas sanitárias, avenidas-canal implantadas ao longo dos cursos de água, a constituição de espaços públicos e valorização das paisagens pitorescas das cidades. "Um suposto defeito de plano, um acidente topográfico, se transformam em belezas quando o profissional competente as sabe criar ou expor à vista dos transeuntes" (BRASIL, 1943b).

Daniel Tochetto de Oliveira (2013) pontua que Saturnino de Brito definiu que a necessidade era a circulação, abrir ruas, criar avenidas, elementos incompatíveis com o traçado irregular das cidades antigas. As necessidades da vida moderna não poderiam mais se adaptar aos traçados irregulares da maioria das cidades antigas, pelo menos nos novos bairros. Algumas alterações eram importantes, como promover a abertura de espaços, o alargamento de ruas e avenidas. Mas, para suprir as necessidades da vida moderna, era preciso um plano de melhoramentos urbanos.

Além de planejar, embelezar e sanear as cidades tomadas ou sob ameaça de epidemias, o urbanismo sanitarista de Brito concedeu às cidades brasileiras um novo padrão estético, moderno e progressista, além de formas urbanas próprias de uma tecnologia de saneamento cuja implantação se tornou, durante toda a Primeira República, um dos pilares do Estado Novo. André Luís Borges Lopes (2013) complementa ao considerar que, a partir da consolidação da nova ordem republicana, as principais cidades brasileiras passaram por um processo de modernização e urbanização relacionados ao novo projeto político das elites no poder. Esse rearranjo espacial e social estava baseado em novos paradigmas de higienização e embelezamento franceses.

Saturnino de Brito defendia como tarefa fundamental de qualquer cidade a obrigação de prever a expansão da rede sanitária e dos arruamentos. Para Carlos Roberto Monteiro de Andrade (1992), Brito afirmava que a necessidade de se elaborar planos gerais de expansão se dava por três fatores: evitar que o crescimento da cidade acontecesse ao acaso, extirpar os conflitos entre interesses privados e públicos e conceder maior longevidade às obras de saneamento, para que elas não fossem comprometidas futuramente.

Mediante contexto de planejamento geral desenvolvido por Saturnino de Brito, era fundamental realizar um levantamento prévio da cidade existente. Para tanto, Brito desenvolveu uma metodologia ampla para levantamentos e diagnósticos da área a ser estudada, importantes para a organização dos projetos: levantamento topográfico preciso, ruas e becos a serem alargados, locais pitorescos a serem preservados, áreas para jardins e parques, áreas para uma futura expansão da cidade, levantamentos cadastrais, características econômicas, planos e posturas municipais elaborados anteriormente, população, vegetação, clima, salubridade, bem como causas de insalubridade, situação atual dos serviços urbanos, condições sanitárias, mananciais a serem preservados, natureza das águas, mensuração do volume de água requisitado, indicações precisas das condições de descarga dos despejos, atitudes da população do ponto de vista higiênico, condições das moradias, tipos de instalações nas residências e condicionantes topográficas (LOPES, 2013).

Assim, caberia ao engenheiro sanitário apresentar em seus planos de melhoramentos urbanos obras que representassem adequadas condições para uma vida saudável, assegurando com suas construções as possibilidades de garantir a higiene da água, do ar, do solo e do corpo. 


\section{O traçado sanitário de Santa Maria/RS: forma, espaço e prática}

Destaca-se como procedimento metodológico uma análise descritivo-interpretativa dos projetos e relatórios de Saturnino de Brito, volume XI, publicados no ano de 1943 pelo Ministério da Educação e Saúde do Brasil. Esta obra, fonte primária deste artigo, trás os planos de melhoramentos urbanos das cidades de Cachoeira, Passo Fundo, Rosário, Cruz Alta e, objeto de estudo deste artigo, Santa Maria, todas cidades sul rio-grandenses.

A atuação de Saturnino de Brito foi muito ampla se considerado o número de cidades em diferentes estados brasileiros. No entanto, uma delas se destaca nesse cenário: Santos, situada no estado de São Paulo. Não que a ela se atribua um valor maior, mas por cristalizar a prática de Brito em suas diferentes dimensões: traçado, melhoramentos, hidrologia superficial, tratamento de esgotos, obras, entre outras, a análise dessa cidade é necessária para efeito comparativo de entendimento do trabalho dele.

No início do século XX, Santos já era o principal porto de exportação de café, contando com a presença de milhares de trabalhadores atraídos pelas obras e serviços de infraestrutura realizados entre o final do século XIX e os primeiros anos do século $X X$. Essa força de trabalho, formada por imigrantes europeus, migrantes do nordeste e escravos recém-libertos, fixou-se na cidade em condições de remuneração baixas. Assim, reduzia-se a possibilidade de habitarem em locais minimamente adequados sob o ponto de vista sanitário (CARRIÇO, 2013).

Para Andrade (1989), as principais moléstias que dizimaram parte de sua população, como febre amarela, tuberculose, varíola e malária, causaram significativos danos sociais e espaciais. O agravamento das epidemias, que passou a dificultar o comércio cafeeiro, tornou necessário controlar a produção do espaço e a vida cotidiana das cidades, por meio da legislação e de intervenções no meio físico urbano.

Saturnino de Brito apresentou seu plano para o saneamento de Santos no ano de 1905, com a adoção do sistema de separação e execução de uma extensa rede de canais de drenagem e galerias de esgoto, ao mesmo tempo em que o abastecimento de água se ampliava. Para José Marques Carriço (2013), a Santos moderna já nascia amparada por uma rede de infraestrutura suficiente para suportar o adensamento populacional da primeira metade do século XX.

Sem dúvida, o plano de saneamento, melhoramentos e extensão que Saturnino de Brito elaborou e implantou em Santos, ainda que não tenha sido realizado em todos os seus aspectos, não apenas representou a construção de uma cidade moderna, como também a aplicação de princípios urbanísticos inovadores para a época, por meio dos quais o passado colonial da cidade desapareceu em nome de um futuro marcado pela higiene e pelo progresso (ANDRADE, 1991).

Segundo Bernardini (2015), esse plano apresentado por Brito consistia basicamente em três grupos de obras: a primeira referia-se aos esgotos sanitários, isto é, coleta, elevação e emissão da contribuição de despejos por meio da divisão da área em pequenos distritos: descarga in natura em pleno mar ou descarga após depuração no estuário ou barra; a segunda obra consistia na reforma completa das instalações domiciliares; e a terceira e última obra referiam-se aos esgotos pluviais, circulação 
Figura 1: Trecho do canal da rua Rangel Pesata (concreto armado), Santos/SP. Fonte: BERTONI, 2015 b, p. 117. do volume por meio de valas ou sarjetas interceptoras e de caixas de sedimentação, galerias pluviais descarregando diretamente no estuário, canais de drenagem, com avenidas marginais cortando as planícies dos subúrbios e abertos de mar a mar de modo que pudesse acontecer a renovação das águas.

Esse projeto era extremamente detalhado, ocupando-se da largura das vias, estabelecendo recuos e desenhando os equipamentos sanitários internos dos imóveis. Brito estudou o volume e a periodicidade das precipitações pluviométricas em Santos. O regime das águas das chuvas e das marés. A topografia e as calhas naturais de drenagem da ilha de São Vicente. Contudo, Bernardini (2015) revela que a face mais marcante do projeto foram os canais de drenagem, que favoreceram a extensão da cidade sobre uma parte do território frágil em termos ambientais, colocando em evidência o uso da tecnologia pelo homem para adaptar o espaço natural (Figura 1).

As propostas de Brito não se limitaram ao plano de saneamento. No ano de 1910, o engenheiro encaminhou à Câmara Municipal uma planta que consistia num completo plano urbanístico para a cidade de Santos, apoiado nas ideias de Camilo Sitte (Figura 2). Esse novo plano apresentava largas avenidas com amplas áreas verdes. Vários parques e equipamentos sociais e de lazer foram previstos, de modo a dotar a cidade de uma completa rede de serviços. Era um plano completo (BERNARDINI, 2015).

Segundo André Luís B. Lopes (2013), a presença de Saturnino de Brito no Rio Grande do Sul tinha um propósito maior do que simplesmente desenvolver planos de melhoramentos urbanos para as cidades. Para ele, a atuação de Brito iria servir para orientar a formação de um novo projeto no Rio Grande do Sul. Solicitadas no contexto de implantação

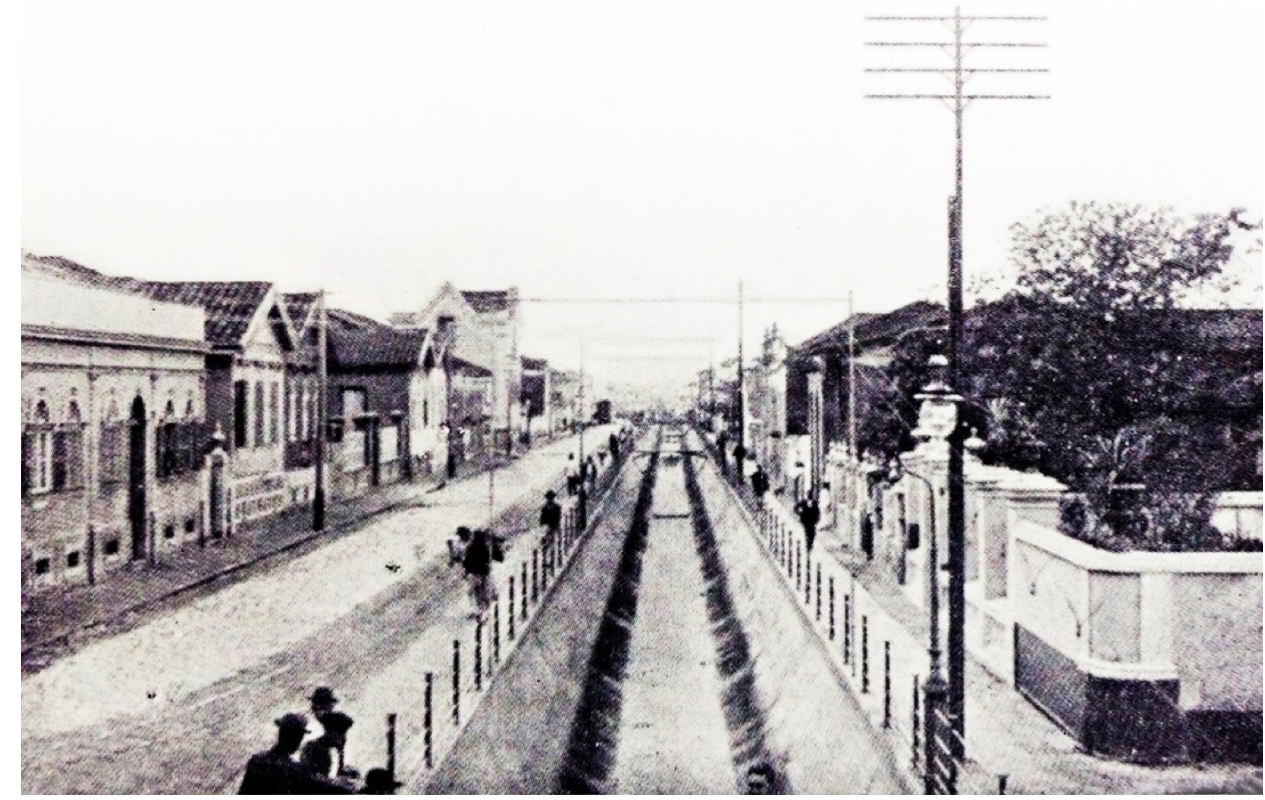




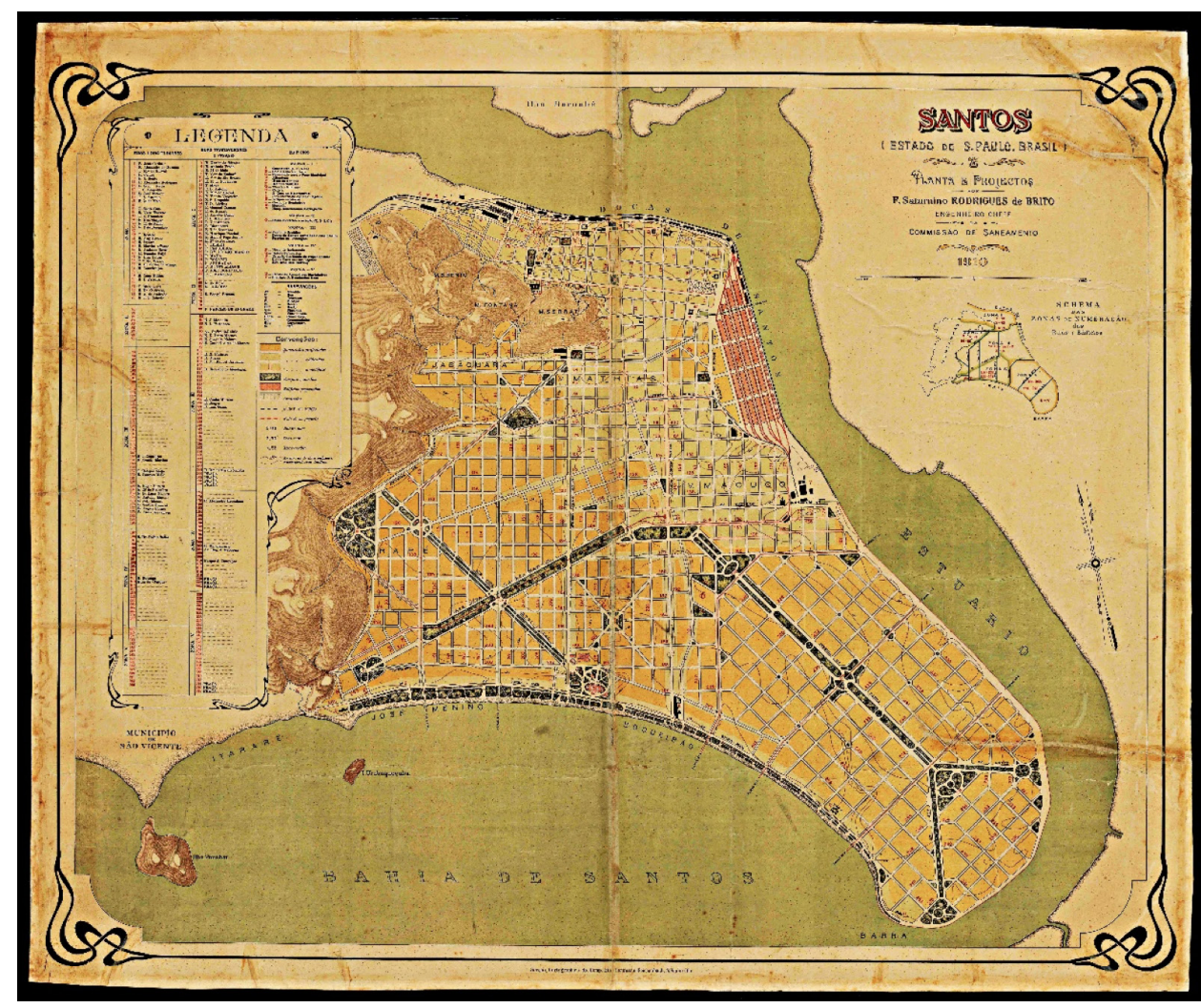

Figura 2: Planta e projetos de Santos elaborados por Saturnino de Brito, 1910. Nesse momento ele era engenheiro-chefe da Comissão de Saneamento da cidade. Nesta imagem é possível observar o projeto de expansão e a rede de canais que cortam a cidade. Fonte: Arquivo Público do Estado de São Paulo. da Primeira República, essas obras surgem com um instrumento político do Partido Republicano Rio-Grandense (PRR) e de seu novo projeto urbano, orientando, assim, o progresso que se estabelecia com a instalação do novo regime. Para tanto, essas obras devem ser analisadas também como um instrumento técnico, respaldadas em estudos técnicos, elaboradas por um especialista bastante sincronizado e atualizado em relação aos conhecimentos daquele momento.

O PRR tinha um projeto capitalista para o Rio Grande do Sul, que previa a modernização econômica e social, especialmente no setor de transportes e no saneamento das cidades. Lopes (2013) revela que, em termos econômicos, esse projeto se traduzia numa proposta de desenvolvimento econômico que contemplasse todos os setores da economia gaúcha. Assim, foi constituído, em 1913, por meio do Decreto n ${ }^{\circ}$ 1.958, de 19 de abril, um amplo plano de desenvolvimento regional dos sistemas de transportes, denominado como Plano Geral de Viação. Este plano tinha como pressuposto criar redes viárias - ferrovias, rodovias e transporte fluvial - para integrar as diferentes cidades e regiões do estado, impulsionando a produtividade do estado, o comércio, a urbanidade, formando novos núcleos urbanos e dotando os já existentes de equipamentos públicos e saneamento.

Tal conjuntura justifica a presença de Saturnino de Brito em mais de 10 cidades do Rio Grande do Sul. O objetivo do PRR era promover um sistema de comércio e transporte entre as cidades; todavia, para que isso pudesse acontecer, era também necessário melhorar a infraestrutura sanitária dessas cidades que comporiam a rede viária do estado. 
A cidade de Santa Maria/RS integrava esse projeto. A ferrovia chegou à cidade ainda em fins do século XIX, mas foi nos anos subsequentes que a cidade passou por um intenso processo de transformações urbanas. A movimentação de passageiros e mercadorias na estação ferroviária aumentou significativamente entre os anos de 1907 e 1913, e tal situação se refletia no espaço urbano. Junto ao desenvolvimento urbano, a Proclamação da República favoreceu a formação de um ambiente propício a essas transformações, em função da autonomia político-econômica.

No intuito de regular essa modernização pela qual a cidade de Santa Maria estava passando, foram previstas diferentes medidas orçamentárias e promulgadas posturas que pudessem garantir o bom convívio, a higiene, a ordem e a organização do espaço urbano da cidade. Uma das medidas, como aconteceu com praticamente todas as cidades, era o alinhamento das novas ruas a serem abertas.

Segundo Daniel Tochetto de Oliveira (2013), a fim de garantir a higiene no espaço urbano, qualquer pessoa que depositasse ou lançasse, nos logradouros ou vias públicas, lixos, águas servidas, animais mortos ou qualquer outro tipo de detrito, assim como qualquer outro tipo de objeto que dificultasse o trânsito público, pagaria uma multa determinada pelo poder público municipal. Oliveira ainda destaca que o primeiro óbito por peste bubônica na cidade aconteceu em 1912, fazendo com que o intendente municipal tomasse algumas medidas, como o fechamento dos colégios e a paralisação das atividades comerciais e sociais.

A situação sanitária da cidade ficava cada vez mais complicada devido à falta de uma infraestrutura adequada. A realidade piorava ainda mais quando chovia, já que as águas pluviais se contaminavam facilmente e passavam por toda a cidade, colocando em risco a vida dos cidadãos de Santa Maria. Era comum essas águas entrarem em contanto com os dejetos e outros tipos de lixos nos quintais das casas ou com os afluentes das fossas. Somente no ano de 1915 foram registradas 92 doenças infectocontagiosas. Em decorrência delas, registraram-se 55 óbitos por tuberculose e 12 por febre tifoide. Em 1918, em razão de sua fragilidade sanitária, a cidade sofreu novamente devido à epidemia de gripe espanhola. As medidas referentes ao estado sanitário da cidade tornavam-se exigentes (OLIVEIRA, 2013) (Figura 3).

Diante dos problemas sanitários da cidade de Santa Maria e da política republicana do PRR, Saturnino de Brito é contratado pela municipalidade para elaborar e executar um plano de melhoramentos urbanos. Segundo Oliveira (2013), o projeto de saneamento para a cidade, acompanhado do relatório, foi entregue por Saturnino de Brito ao Intendente Municipal em 02 de dezembro de 1918. Porém, sua execução aconteceu somente a partir de 1929.

Ao examinar o relatório do plano de melhoramentos para Santa Maria, é possível identificar a prática de Brito e compreender a espacialização da forma urbana empregada pelo profissional. Sua estrutura de análise divide-se em: topografia sanitária (salubridade), abastecimento de água, esgoto pluvial, esgotos sanitários e anexos. É uma estrutura que compreende um conjunto de informações básicas de trabalho. Nesse mesmo período, Saturnino de Brito desenvolveu outros planos de melhoramentos urbanos, além de Santa Maria, para as cidades de Cachoeira, Passo Fundo, Rosário e Cruz Alta, todas situadas no estado do Rio Grande do Sul. 
Figura 3: Esquina da rua dos Andradas com a atual rua Serafim Valandro, início do século XX. Pela figura é possível deduzir como eram as condições de higiene da cidade de Santa Maria. Fonte: OLIVEIRA, 2013, p. 178.

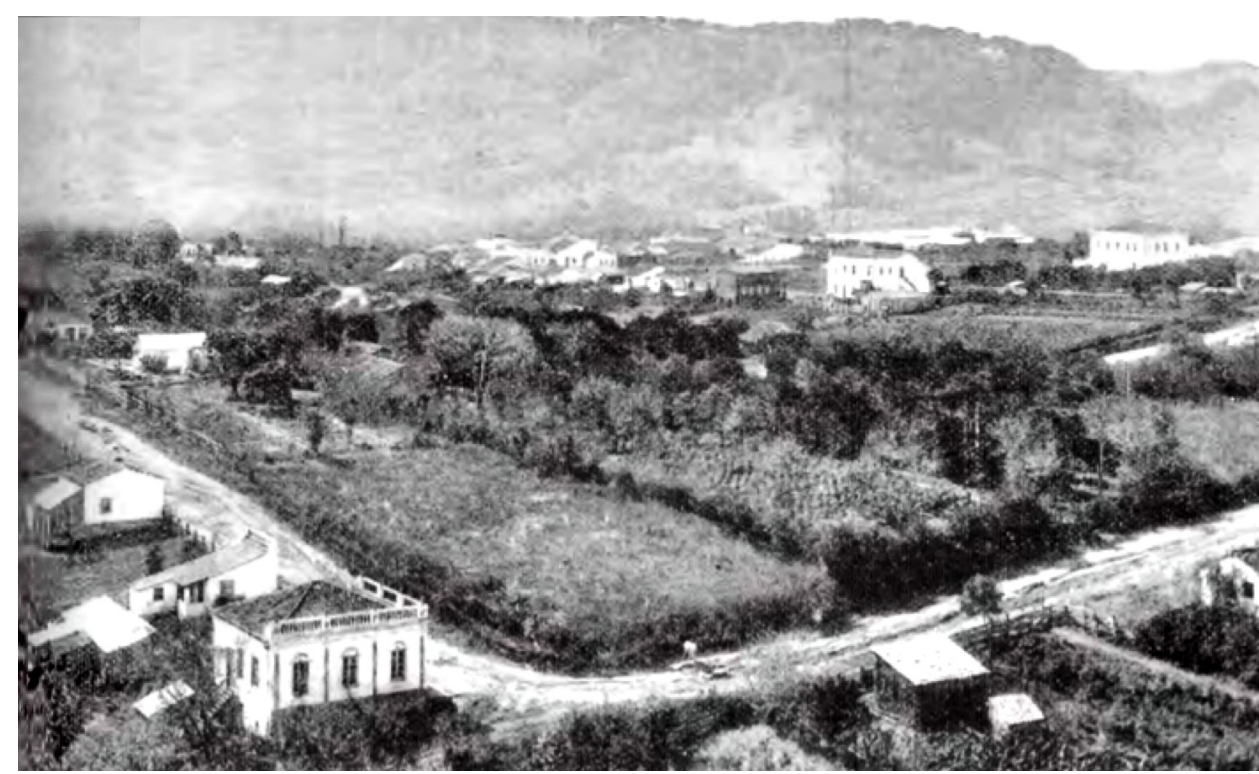

Ildefonso C. Puppi (1981), em suas considerações acerca das noções de composição urbanístico-sanitárias, revela que o planejamento urbanístico, quer se trate da criação de uma nova cidade, quer da reestruturação parcial ou geral de uma cidade existente ou da extensão urbana, implica diferentes estudos preliminares e trabalhos preparatórios para intervir no espaço urbano. Há a necessidade de levantamento de dados, desde os de caráter mais geral, pertinentes às características fisiográficas e condições socioeconômicas regionais, até os de caráter mais especial, relacionados com a formação e a situação atual do núcleo populacional e espacial preexistente.

Assim, são necessárias informações topográficas, hidrográficas, geológicas, climáticas, históricas, demográficas, higiênicas e sanitárias, econômicas e sobre as condições urbanas atuais, ou seja, circulação, zoneamento, espaços livres, zona verde e serviços sanitários. O pesquisador Dirceu Piccinato Junior (2018) quando analisou o plano de melhoramentos urbanos elaborado por Saturnino de Brito para a cidade de Passo Fundo, dando atenção ao projeto de abastecimento de água, observou que o engenheiro se preocupava com todas as dimensões e aspectos de uma cidade. No referido estudo, o pesquisador ressalta que o projeto não buscou apenas resolver as questões de abastecimento de água, mas aspectos ambientais, sociais e da forma espacial urbana de Passo Fundo.

Para conformar o traçado sanitário de Santa Maria, Brito procurou entender a topografia da cidade. Para ele, em seu relatório, o município é montanhoso ao norte, nordeste e noroeste, sendo ondulado na região central e plano nas várzeas. Aponta também que a cidade é edificada, na sua parte central, em um contraforte da Serra Geral que se bifurca em outros secundários, formando-se talvegues de forte declive, chamados "sangas", por onde as águas das chuvas correm em direção a outros cursos d'água que passam pela cidade (BRASIL, 1943b). 
Figura 4: Avenida Rio Branco, 1925. Fonte: OLIVEIRA, 2013, p. 199.
É interessante observar que o engenheiro registra que, devido à posição estratégica da cidade - pois a partir dela partiam as linhas férreas para São Paulo, Porto Alegre e Rio Grande -, ela se destacava em relação à política, ao comércio e à estruturação sanitária, estabelecendo boas condições de salubridade, já que passava por diversos problemas com as epidemias e os registros de mortes. Sob tal perspectiva, Brito ponderou que as condições altimétricas e planimétricas da cidade eram favoráveis à salubridade.

Estão registrados em seu relatório que as principais ruas da cidade, traçadas em linha reta, foram direcionadas junto à lombada do contraforte, na direção leste-oeste, de maneira que as demais ruas possuem direção norte-sul. Para ele, esse tipo de traçado reticular aplicado na planimetria da cidade, sem as diagonais que facilitariam a distribuição do trânsito, era muito inconveniente. O engenheiro compara a situação complicada desse traçado com qualquer outro tipo de traçado irregular pensado a partir do efeito estético de ruas tortuosas. Ele ainda complementa, revelando que preferiria "o erro da simetria original", ou seja, o traçado reticulado, em linha reta, pois resulta em um certo número de vantagens utilitárias e "ele não impede a ulterior intervenção do senso estético" (BRASIL, 1943b, p. 15).

Nessa análise prévia acerca do traçado da cidade, o engenheiro observa que, nas ruas retas, traçadas sobre um terreno fortemente acidentado, observam-se como predicados estéticos a sucessão de rampas e as diferentes e interessantes perspectivas que um observador possa ter da paisagem natural e construída de Santa Maria. Saturnino de Brito (BRASIL, 1943b) destaca que as ruas são geralmente largas, como a avenida Rio Branco, com seus $44 \mathrm{~m}$ de largura e arborizada (Figura 4).

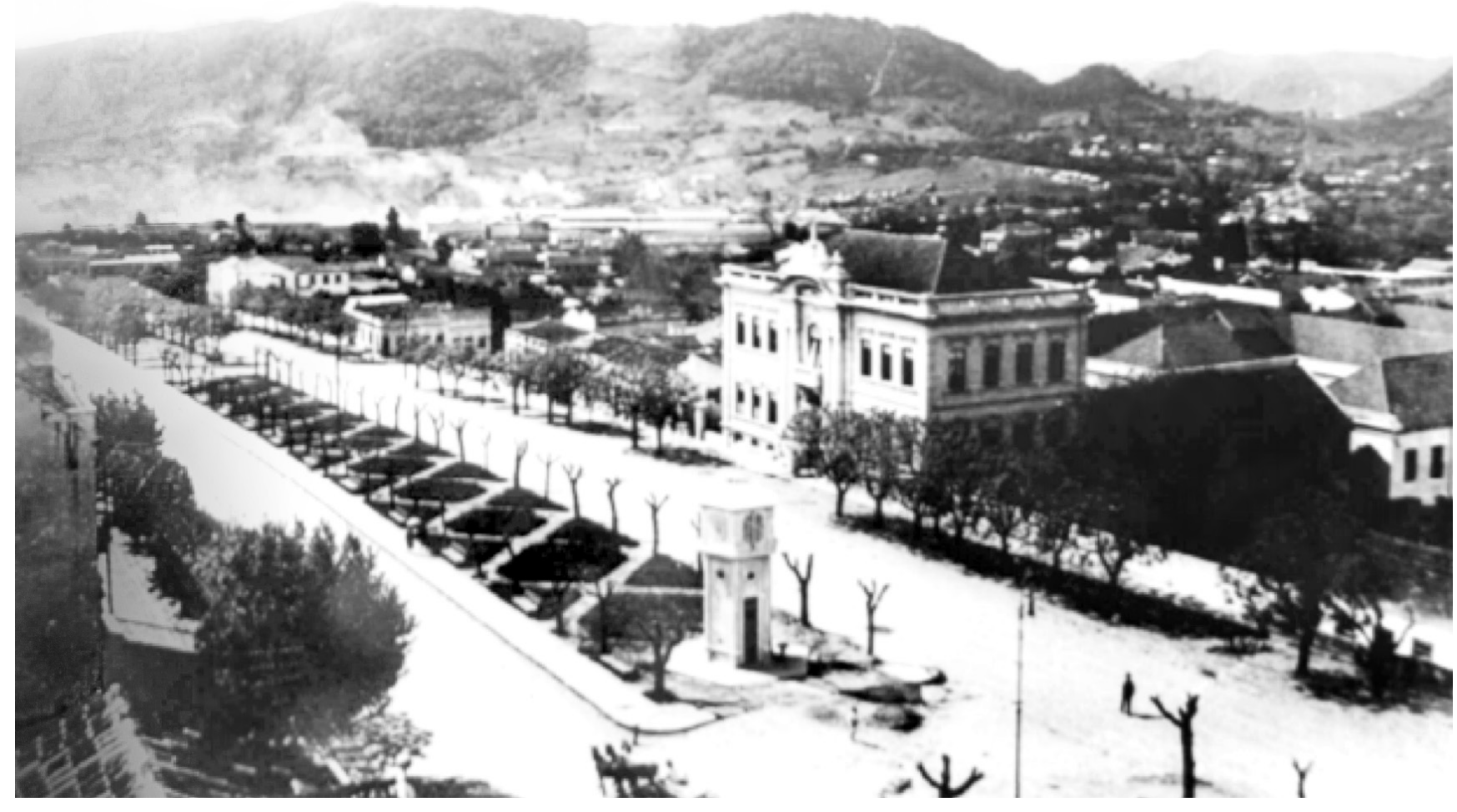


Ainda no relatório, Brito (BRASIL, 1943b) destaca que, em um grande trecho de ruas, as declividades são fortemente acentuadas, desfavoráveis ao trânsito de veículos e à conservação, considerando o fato de que muitas delas não estão calçadas e as águas pluviais geram severos danos. Essas ruas pendem para os cursos d'água que se encontram na malha urbana da cidade, de forma que as águas da chuva crescem rapidamente e correm com excessiva velocidade, provocando estragos nas ruas e no curso dessas sangas.

Segundo as colocações acima, pode-se conjecturar que a disposição dos terrenos denota que o esgotamento das águas das chuvas se fazia naturalmente pelas sarjetas das ruas e pelos talvegues. Todavia, mesmo apresentando essa vantagem, é importante apontar que, durante as chuvas, esses cursos d'água também recebiam os esgotos das casas; tal situação causava a contaminação da água dos moradores que moravam próximos desses cursos de água por moléstias contagiosas.

Para a estruturação do traçado sanitário de Santa Maria, Brito imprimiu referências de seu livro Le Tracé Sanitaire de Villes. O engenheiro planejou ruas sinuosas para as áreas de expansão urbana e locais onde não era necessário o deslocamento rápido. Brito as considerava, do ponto de vista estético e técnico, as mais indicadas para terrenos com topografia acidentada, porque se adaptavam às curvas de nível, permitindo a fluidez do trânsito, bem como o escoamento das águas e os interessantes efeitos perspectivos, frutos das ruas sinuosas e lugares pitorescos (BRASIL, 1943a).

Essa obra literária marca o auge do pensamento de Saturnino de Brito. Nela, ele aborda diferentes tipos de organização espacial e aspectos legislativos que deveriam acompanhar a implementação dos planos de melhoramentos urbanos. Para ele, o traçado sanitário de uma cidade deve afirmar a eficiência da abordagem urbana da engenharia sanitária. Assim, a construção de redes técnicas e viárias adaptadas à topografia tornava-se o suporte privilegiado para a expansão urbana e a reestruturação sanitária dos ambientes preexistentes (BRASIL, 1943a).

Brito (BRASIL, 1943b) ainda ressaltou que esse tipo de estrutura para a cidade permitiria o emprego de condutos de pequeno diâmetro, os quais ficariam dispostos em valas pouco profundas. Porém, os inconvenientes desse processo seriam ocasionados pelos esgotos domiciliares das casas que estivessem localizados em terrenos inclinados para os cursos d'água. Segundo o engenheiro, na época, essas casas tinham lavanderias e banheiros situados em uma cota muito inferior em relação à rua da frente; nesse sentido, deveriam ser instalados coletores gerais a consideráveis profundidades pelos fundos dessas casas.

O plano de melhoramentos de Brito foi elaborado em cima da planta de Santa Maria traçada em 1931 e completada com demais estudos, particularmente o topográfico. É perceptível a diferença entre os traçados, o anterior e o proposto por Saturnino de Brito para a cidade (Figura 5).

O traçado proposto pelo engenheiro buscou evitar a monotonia das vias retas e longas. Ele elaborou cruzamentos e áreas destinadas a espaços públicos ou equipamentos sanitários. Embora não estejam identificados no plano da cidade, muitos desses espaços foram indicados para serem parques e praças. Para Santa Maria, Brito não deixou claro 


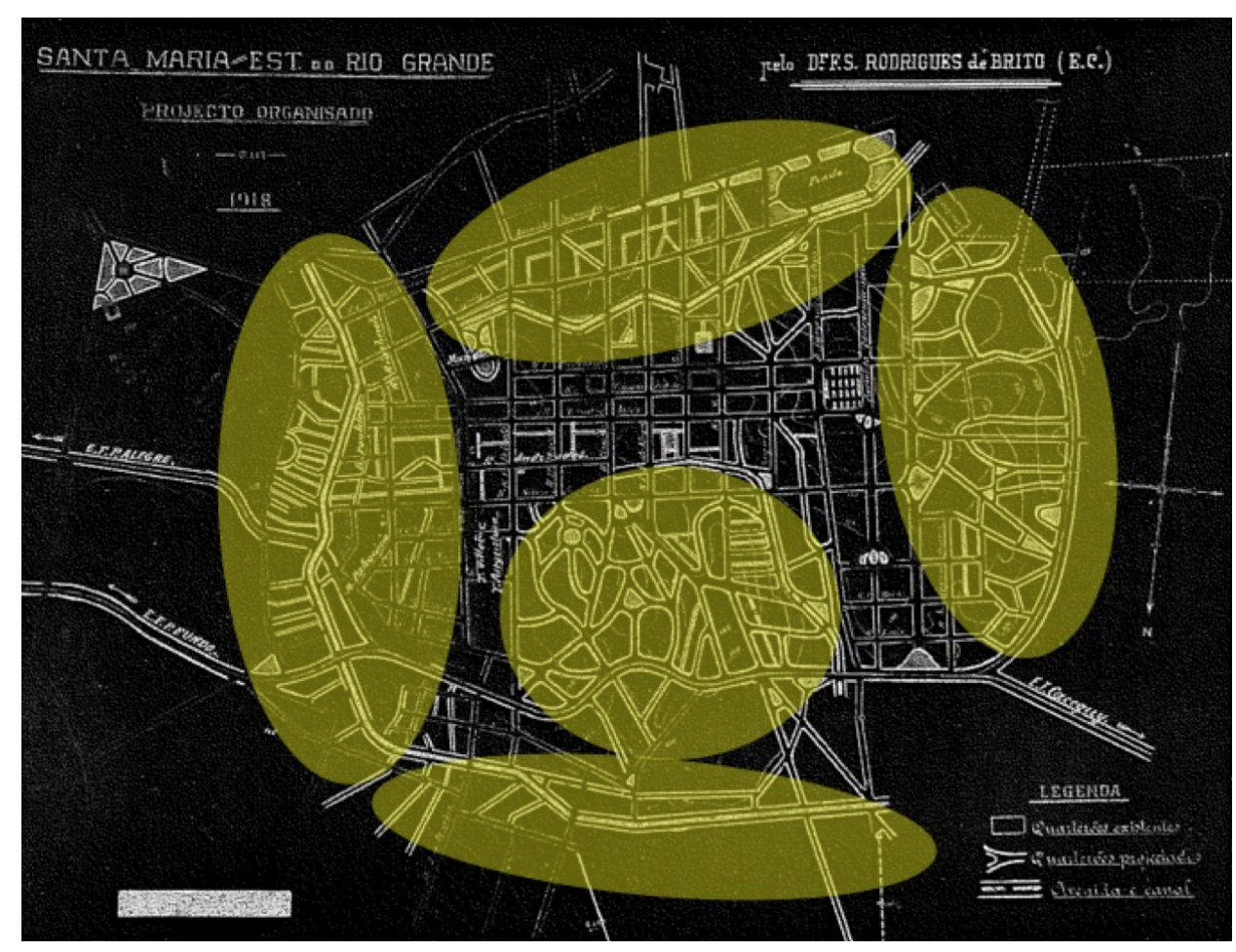

Figura 5: Adaptado pelo autor, em negativo, o plano de melhoramentos urbanos para a cidade de Santa Maria/RS, elaborado por Saturnino de Brito em 1918. Nesse "projecto" podem-se observar o traçado original da cidade, em retícula, e o traçado para a expansão da cidade (manchas na cor amarela), seguindo uma conformação orgânica, respeitando e configurando-se a partir da topografia. Fonte: BRASIL, 1943 b, p. 18. se seria possível a navegação nos canais das avenidas, como aconteceu com a cidade de Santos. A diferença de traçado no plano de melhoramentos é notória e configura quatro áreas de expansão urbana, para onde a cidade poderia se desenvolver de modo organizado e ter os seus respectivos serviços de saneamento garantidos.

Analisando a planta acima, pode-se verificar que o traçado da cidade de Santa Maria foi estruturado considerando três dimensões de expansão, isto é, os quarteirões existentes, os quarteirões projetados e as avenidas e canais, como se pode observar na legenda abaixo da planta, no lado direito. Examinando o relatório e o traçado sanitário da cidade, pode-se contextualizar que o plano de melhoramentos representa um diálogo entre aspectos técnicos e artísticos da disciplina urbanismo, em construção nesse momento. Esse plano pode ser compreendido também como uma síntese do ideário de Brito, baseando-se na posição de alguns técnicos estrangeiros, particularmente de Camillo Sitte.

\section{Considerações finais}

É oportuno resgatar neste momento algumas considerações estudadas anteriormente. O termo cidade demandou e demanda análises e entendimento, já que é fundamental contextualizar qual cidade, em suas diferentes escalas e processos, se está analisando. Para a primeira metade do século XX, a cidade que se discute não é aquela que está associada à dimensão, mas, fundamentalmente, aos grupos sociais que definem os contrastes dos espaços urbanos. É a elite e o saber erudito que foram responsáveis pela configuração e reconfiguração das cidades brasileiras. 
Nesse cenário destacam-se a presença de técnicos e seus diferentes saberes; como já apontado acima, Saturnino de Brito é a referência em relação à engenharia sanitária. Para propor planos e reestruturar espaços da cidade preexistente, o engenheiro teve como eixo ordenador a dimensão dos fluxos da cidade. Para tanto, não se pode olvidar que um plano de melhoramentos urbanos era composto por saneamento, embelezamento e circulação. A cidade de Santos tornou-se um paradigma dentro do ideário urbano-sanitarista.

Se Saturnino de Brito não criou um modelo de trabalho, pode-se considerar que tenha desenvolvido uma prática de atuação junto aos projetos que elaborou. Essa prática apontou que, para se estabelecer uma estrutura sanitária, ou seja, uma forma urbana adequada para a nova realidade urbana que se descortinava, a topografia sanitária era o primeiro elemento a ser considerado. A partir do entendimento das linhas topográficas, a cidade poderia acontecer ou por meio de linhas retas, ou por intermédio de linhas simétricas, apresentando conformidade, posição e forma relativa entre as partes.

Finaliza-se ponderando que Santa Maria é síntese dessa realidade, desse pensamento que agrega o respeito ao traçado original e ao traçado novo, modernizante e progressista. A conformação urbana elaborada por Saturnino de Brito para a cidade representa o "projecto" como expressão da forma urbana. Nessa cidade também nos é permitido compreender o espaço construído e proposto como registro do discurso e da prática de um tempo.

\section{Referências bibliográficas}

ANDRADE, W. T. F. de. O discurso do progresso: a evolução urbana de Santos, 1870 - 1930, FFLCH-USP: São Paulo, 1989.

ANDRADE, C. R. M. de. O plano de Saturnino de Brito para Santos. Espaço e Debates, 34, 55-63, 1991.

A peste e o plano: urbanismo sanitarista do Eng. Saturnino de Brito, FAU-USP: São Paulo, 1992.

BERNARDINI, S. P. A dureza do fazer. A práxis na urbanística de Saturnino de Brito a partir do seu plano de saneamento para a cidade de Santos (1905-1910), Risco Revista, 13, 47-62, 2015.

BERTONI, A. A engenharia sanitária a serviço do urbanismo: a contribuição de Saturnino de Brito e Victor da Silva Freire para a construção dos saberes urbanos. Risco Revista, 13, 74-83, 2015a.

No caminho para o urbanismo. Saturnino de Brito e Édouard Imbeaux, trajetórias profissionais entre Brasil e França. Anais do Museu Paulista: História e Cultura Material, V. 23, n. 1, 111-132, 2015b.

BRASIL. M. da E. e S. Urbanismo. Traçado Sanitário das Cidades. Estudos Diversos, v. XX, Imprensa Nacional: Rio de Janeiro, 1943a.

Projetos e Relatórios. Saneamento de Santa Maria, Cachoeira, Passo Fundo, Rosário e Cruz Alta, v. XI, Imprensa Nacional: Rio de Janeiro, 1943b.

BRESCIANI, M. S. Melhoramentos entre intervenções e projetos estéticos: São Paulo (18501950). In M. S. Bresciani (org.) Palavras da Cidade. Ed. Universidade/UFRGS: Porto Alegre, 343-366, 2001. 
CARRIÇO, J. M. O plano de Saturnino de Brito para Santos: urbanismo e planejamento urbano entre o discurso e a prática. In C. de CAMPOS; F. ATIQUE; G. A. F. DANTAS (orgs.) Profissionais, práticas e representações da construção da cidade e do território. Alameda: São Paulo, 2013.

DANTAS, A. C. de C. L. Sanitarismo e planejamento urbano: a trajetória das propostas urbanísticas para Natal entre 1935 e 1969. UFRN: Natal, 2003.

GITAHY, M. L. C. (org.). Desenhando a cidade do século XX. RiMA/Fapesp: São Carlos, 2005.

LEME, M. C. Da S. (org.). Urbanismo no Brasil: 1895 - 1965. Studio Nobel; FAU-USP; Fupam: São Paulo, 1999.

LOPES, A. L. B. "Sanear, Prever e Embelezar": o engenheiro Saturnino de Brito, o urbanismo sanitarista e o novo projeto urbano do PRR para o Rio Grande do Sul (1908 - 1929). PUCRS: Porto Alegre, 2013.

OLIVEIRA, D. T. de. A cidade de Santa Maria e o saneamento de Saturnino de Brito. UFRGS: Porto Alegre, 2013.

PANERAI, P.; CASTEX, J.; DEPAULE, J. Formas urbanas: a dissolução da quadra. Bookman: Porto Alegre, 2013.

PEREIRA, P. C. X. Cidade: sobre a importância de novos meios de falar e de pensar as cidades. In M. S. Bresciani (org.) Palavras da Cidade. Ed. Universidade/UFRGS: Porto Alegre, 261284, 2001.

PICCINATO JUNIOR, D. Saturnino de Brito e o projeto de abastecimento de água para a cidade de Passo Fundo-RS. Cadernos de Arquitetura e Urbanismo (PUCMinas), 36, 16-56, 2018.

PUPPI, I. C. Estruturação sanitária das cidades. UFPR/CETESB: Curitiba/São Paulo, 1981.

SIMÕES JUNIOR, J. G. O ideário dos engenheiros e os planos realizados para as capitais brasileiras ao longo da Primeira República. In C. de CAMPOS; F. ATIQUE; G. A. F. DANTAS (orgs.) Profissionais, práticas e representações da construção da cidade e do território. Alameda: São Paulo, 2013.

\section{Agradecimentos}

À Fundação Meridional e ao grupo de pesquisa THAC-IMED, Passo Fundo/RS, pelo apoio irrestrito ao desenvolvimento deste trabalho. 